\title{
DIMENSIONANDO AS DESIGUALDADES POR SEXO E COR/RACุA NA PÓS-GRADUAÇÃO BRASILEIRA
}

\author{
AMÉLIA ARTES ${ }^{*}$ \\ ORCID: https://orcid.org/0000-0001-7296-9820
}

\begin{abstract}
RESUMO: O uso de indicadores para dimensionar desigualdades sociais tem se disseminado de forma mais intensa nas últimas décadas em estudos da área das ciências humanas. Trazer esse instrumental para a análise das mudanças ocorridas na participação de mulheres e negros nos cursos de graduação e pós-graduação, tem considerável importância em face da implementação de políticas de ação afirmativa que objetivaram a ampliação do acesso ao ensino superior de grupos sociais sub-representados, em especial os negros e indígenas. Este estudo apresenta os índices de Paridade de Gênero (IPG) e Paridade Racial (IPR) como instrumentos auxiliares na caracterização do público que acessou e frequentou a graduação e pós-graduação no período 2000-2010, a partir das informações fornecidas pelos Censos Demográficos de 2000 e 2010. Observa-se, nos resultados obtidos, que o acesso é tanto diferenciado por sexo como por cor/raça, com piores indicadores para os negros.
\end{abstract}

Palavras Chave: Desigualdades. Indicadores. Gênero: cor/raça.

\section{DIMENSIONING INEQUALITIES BY SEX AND COLOR: RACE IN BRAZILIAN POST-GRADUATION}

ABSTRACT: The use of indicators to measure social inequalities has been disseminated more intensely in the last few decades through social science research. Bringing these instruments to analyze the changes that have occurred in women and black people's participation in undergraduate and graduate education is extremely important in light of the implementation of affirmative action policies that aimed to provide poorly represented social groups with broader access to college education, particularly blacks and indigenous people in Brazil. This study presents the indexes of gender and racial parity as instruments to help characterize who had access to and attended undergraduate and graduate school between 2000 and 2010. The results showed that access is differentiated both by gender and race, with some of the worst indicators for blacks.

Keywords: Inequalities. Indicators. Gender: color/race.

\footnotetext{
${ }^{1}$ Fundação Carlos Chagas, São Paulo, SP, Brasil.

"Doutora em Educação pela Universidade de São Paulo. Pesquisadora na Fundação Carlos Chagas. E-mail: $<$ aartes@fcc.org.br >.
} 


\section{INDICADORES SOCIAIS E MEDIDAS DE MONITORAMENTO}

A construção de indicadores numéricos para monitoramento de políticas sociais tem sua origem nos anos 1960 nos Estados Unidos, em um contexto da crise do Welfare State, em que se faziam necessários estudos teóricos e empíricos que relacionassem qualidade de vida e planejamento governamental. Entre 1970 e 1980, organismos internacionais, como a Organização das Nações Unidas (ONU), a Organização de Cooperação e Desenvolvimento Econômico (OCDE), entre outros, desenvolveram e reproduziram um conjunto de indicadores sociais visando operacionalizar a mensuração do bem-estar, a exemplo da taxa de mortalidade infantil, do índice de desenvolvimento humano (IDH) e do índice de liberdade humana (ILH) (SOLIGO, 2012; SANTAGADA, 1993).

No Brasil, ficou a cargo do Instituto Brasileiro de Geografia e Estatística (IBGE) o desenvolvimento de indicadores sociais, construídos a partir do final dos anos 1970. Segundo Santagada (1993, p. 250), o II Plano Nacional de Desenvolvimento (PND) 1975-1979 "reconhecia o agravamento da problemática social e propunha uma política de redução das desigualdades sociais e econômicas". Desse modo, a criação de indicadores foi desenvolvida para mensurar e monitorar as políticas públicas em desenvolvimento.

O objetivo da construção de indicadores sociais é medir os níveis de bem-estar material de grupos "vulneráveis", permitindo a proposição de políticas públicas. Segundo Jannuzzi (2005, p. 138), os "indicadores apontam, indicam, aproximam, traduzem em termos operacionais as dimensões sociais de interesse definidas a partir de escolhas teóricas ou políticas realizadas anteriormente".

Nos anos 1980 e 1990, a tendência que já se verificava mundialmente foi seguida pelo Brasil com o desenvolvimento de diferentes indicadores, tanto por parte de órgãos governamentais - a exemplo do Indicador Municipal de Desenvolvimento Social (IMDE), elaborado pelo Instituto Nacional de Estudos e Pesquisas Educacionais Anísio Teixeira (Inep), e do Índice de Qualidade de Vida Urbana (IQVU), produzido pela Prefeitura de Belo Horizonte -, quanto de órgãos não governamentais - como o Índice de Desenvolvimento Humano Municipal (IDH-M), concebido pela Fundação João Pinheiro, e o Índice de Vulnerabilidade Juvenil (IVJ), criado pela Fundação Seade.

$\mathrm{Na}$ área da Educação, os indicadores têm sido amplamente utilizados. Um exemplo disso é a produção de relatórios mundiais de monitoramento de políticas educacionais pela Organização das Nações Unidas para a educação, a ciência e a cultura (Unesco). Em 
âmbito nacional, em 2007 o governo federal desenvolveu o Índice de Desenvolvimento da Educação Básica (Ideb), ${ }^{1}$ que tem sido empregado na fixação e verificação do cumprimento de metas de desempenho em escolas de educação básica por todo o país.

Os indicadores apresentados no presente estudo têm como principal objetivo dar visibilidade a dois marcadores sociais: o sexo e a cor/raça para um grupo específico da população brasileira, as pessoas graduadas, os estudantes de pós-graduação e os titulados na pósgraduação. No comparativo com outros indicadores sociais, os aqui descritos são de construção simples: a proposta é descrever a diferença observável entre as variáveis (acesso e finalização das etapas do ensino superior) comparando os resultados entre mulheres e homens, negros e brancos. Apesar da apresentação de informações para outros níveis de escolaridade, neste estudo o foco é a pós-graduação.

\section{ÍNDICES NA EDUCAÇÃO: AS MARCAS DAS DESIGUALDADES}

A questão das desigualdades no acesso à educação segundo sexo e cor/raça já foi tratada por vários autores (ARTES e CARVALHO, 2010; CARVALHO, 2009; ROSEMBERG, 2002). É importante ressaltar que discutir o acesso ou a conclusão de etapas de escolarização nos recortes de gênero e pertencimento racial não consiste apenas em quantificar as diferenças observadas entre os grupos, é necessário incorporar ao debate questões de poder presentes nas relações sociais e que hierarquizam homens e mulheres, brancos e negros. Outra questão, relevante, que sai do escopo do trabalho, refere-se ao enfrentamento de experiências de racismo e sexismo e/ ou discriminação racial/sexual vivenciadas pelos negros e mulheres, presentes em diferentes espaços sociais, entre esses, a academia.

Em especial para os negros, é importante considerar também as políticas de ação afirmativa, ${ }^{2}$ consolidadas nos últimos 10 anos e que foram adotadas por governos (tanto na esfera federal como estadual) e instituições de ensino privadas no Brasil, estas últimas, como prestadoras de serviço, com vistas a diminuir as diferenças sociais entre brancos, negros e indígenas. Essas medidas políticas são fruto de pressões sociais iniciadas nos anos 1990, que foram fortalecidas por meio de legislação específica (Estatuto da Igualdade Racial, Lei n. 12.288/10 e Lei de Cotas, Lei n. 12.711/12). Nas instituições privadas, o Programa Universidade para Todos (Prouni) e o Fundo de Financiamento Estudantil (Fies) ${ }^{3}$ privilegiam, em seus processos de ingresso, o atendimento desses grupos "historicamente minoritários" no acesso ao ensino superior. 
Apesar da ampliação na participação de negros no ensino superior, questões envolvendo racismo/discriminação ainda estão presentes e devem se tornar visíveis. Para tanto, dois caminhos podem ser seguidos: as discussões sobre a diversidade cultural, presente em diferentes espaços da sociedade brasileira, descritas por Munanga (2003); Gomes (2011) e Silvério (2004) e/ou os estudos sobre desigualdades no acesso, permanência e conclusão do ensino superior que podem ser dimensionadas numericamente de acordo com Beltrão e Teixeira (2004) e Paixão (2010), entre outros autores. É nesse segundo caminho que este trabalho se insere.

Explicitar essas diferenças de forma quantitativa e dar visibilidade às distâncias existentes entre os grupos é um primeiro passo para conhecer a realidade e, então, propor políticas de alteração das desigualdades observadas.

Segundo Soligo (2012) dois aspectos são fundamentais na construção de um indicador social:

O primeiro é a escolha de qual aspecto da realidade será tratado. O segundo é definir qual o conceito abstrato que será utilizado para explicação do fenômeno estudado (pag. 17).

Os dois aspectos estão presentes nos indicadores utilizados nesse estudo.

$\mathrm{Na}$ literatura brasileira, a diferença entre homens e mulheres é quantificada a partir de dois indicadores: o índice de paridade ${ }^{4}$ de gênero (IPG) e a razão de sexo.

O IPG é utilizado pela Unesco em seus relatórios de monitoramento global "Educação para Todos" (EPT) com vistas a verificar o cumprimento das metas firmadas em Dacar em 2000. Representa, quantitativamente, a razão mulher/homem para determinada variável escolhida (presença no mercado de trabalho, em cargos de chefia, taxas de escolarização ou titulação, entre outros). Um IPG com valor 1 indica paridade entre os sexos; um IPG que varia de 0 a 1 significa uma disparidade em favor dos homens; um IPG superior a 1 evidencia disparidade em favor das mulheres (UNESCO, 2003/2004, p. 386). Aceitam-se valores entre 0,95 e 1,05 como intervalo de confiança; assim, qualquer indicador inferior a 0,95 representa uma desigualdade para mulheres e qualquer indicador superior a 1,05, uma vantagem para as mulheres.

No último relatório EPT (UNESCO, 2015), é apresentado um conjunto de informações organizadas por IPG. O foco de discussão do relatório, assim como das ações desenvolvidas pelo organismo internacional, é a melhoria da educação básica, com especial atenção 
para o acesso e a permanência das crianças nos primeiros anos de escolarização. No entanto, estão disponibilizados alguns dados sobre o ensino superior. A tabela 1 apresenta o IPG determinado pelo quociente entre a taxa bruta feminina e masculina de escolarização no ensino superior para um conjunto de países selecionados.

TABELA 1. Índice de Paridade de Gênero (IPG) relativo à Taxa Bruta de escolarização no Ensino Superior para 1999 e 2005.

\begin{tabular}{l|c|c}
\hline \multirow{2}{*}{\multicolumn{1}{c|}{ País }} & \multicolumn{2}{|c}{$\begin{array}{c}\text { IPG obtido a partir da Taxa Bruta de } \\
\text { Escolarização no Ensino Superior (TBE) }\end{array}$} \\
\cline { 2 - 3 } & $\mathbf{1 9 9 9}$ & $\mathbf{2 0 0 5}$ \\
\hline Angola & 0,63 & 0,66 \\
\hline Argentina & 1,63 & 1,41 \\
\hline Austrália & 1,22 & 1,25 \\
\hline Brasil & $\mathbf{1 , 2 6}$ & $\mathbf{1 , 3 2}$ \\
\hline Chile & 0,91 & 0,96 \\
\hline Espanha & 1,18 & 1,22 \\
\hline Estados Unidos & 1,31 & 1,40 \\
\hline Japão & 0,85 & 0,89 \\
\hline Noruega & 1,40 & 1,54 \\
\hline Turquia & 0,68 & 0,74 \\
\hline
\end{tabular}

Fonte: Unesco (2015, p. 346-350). Tabela publicada em Artes (2015, p. 23).

A leitura do quadro fica mais fácil ao considerar que para o Brasil, em 1999 de cada 100 homens matriculados no ensino superior tem-se 126 mulheres, valor que chega a 132 em 2005.Os valores demostram que, nas diferentes regiões apresentadas, as mulheres predominam no ensino superior, tanto em 1999 como em 2005, com um IPG acima de 1. A exceção é verificada em países como Angola, Japão e Turquia, porém com tendência de paridade. Nos seis anos, a Argentina foi o único país da seleção em que a tendência foi de queda na participação feminina, de 1,63 para 1,41.

A razão de sexo, utilizada, entre outros, por Beltrão e Teixeira (2004), tem o mesmo princípio de razão numérica, porém apresenta o valor masculino em relação ao valor feminino (inverso do IPG). Neste estudo, optou-se pela utilização do IPG por se considerar que, se o objetivo do indicador é apresentar uma distância - no caso, entre mulheres e homens -, e que quanto mais próxima do valor de paridade, no caso 1, melhor a condição descrita para as mulheres. A diferença entre o valor encontrado e 1 é o que precisa ser melhorado para se alcançar a desejada paridade entre os sexos; com indicadores acima de 1, a desigualdade passa a ser desfavorável para os homens. 
No caso da educação, observa-se que os homens apresentam os piores indicadores, ao contrário dos IPGs construídos para outros espaços sociais, como mercado de trabalho, participação política, entre outros. A análise dos IPGs por áreas de formação mostra diferenças relevantes, associadas às ocupações profissionais diferenciadas para homens e mulheres (RICOLDI; ARTES, 2015; BELTRÃO; TEIXEIRA, 2004).

Espelhando-se no IPG, o Índice de Paridade Racial (IPR) substitui as categorias da variável sexo por categorias da variável cor/ raça: um indicador numérico para os negros na proporção do indicador para os brancos. Rosemberg (2006) apresenta o Indice de Negritude utilizando o mesmo princípio. Não foram encontradas referências internacionais de indicadores que mensurassem as diferenças por cor/ raça ou etnia. Beltrão e Teixeira (2004), em estudo já citado, apresentam a razão padronizada de grupos de cor/raça para qualquer das opções de cor/raça descritas na base de dados (brancos, pretos, pardos, amarelos e indígenas). A decisão por especificar as distâncias entre brancos e negros, na variável escolaridade para os níveis selecionados, tem por objetivo informar sobre a participação dos negros no ensino superior e na pós-graduação brasileira, em um contexto de discussão e implantação de políticas diferenciadoras, as ações afirmativas, para o acesso a graduação e mais recentemente para a pós-graduação. Outros estudos organizam suas informações polarizando os grupos em "brancos" e "não-brancos" (ANDRADE e DACHS, 2007; MAGALHÃES, 2009; Observatório da Metrópole 13, 2013); ${ }^{6}$ ou negros e não-negros (DIEESE, 1999; SANTOS, 2005; SEADE, 2012).

O cálculo utilizado para a produção dos indicadores de IPR segue a fórmula:

QUADRO 1. Cálculo do indicador IPR

$$
I P R_{k t}=\frac{G_{n k t} / N_{k t}}{G_{B k t} / B_{k t}}
$$

sendo $I P R_{k t}$ : o valor do IPR calculado para a faixa etária $k$ e no ano $t$ (2000 e 2010);

$N_{k t}$ : número de negros na faixa etária $k$ e no ano $t$;

$B_{k t}:$ número de brancos na faixa etária $k$ e no ano $t$;

$G_{N k t}:$ número de graduados negros na faixa etária $k$ e no ano $t$ e

$G_{B k t}$ : número de graduados negros na faixa etária $k$ e no ano $t$. 
Para cada um dos indicadores construídos os valores podem ser ajustados para graduandos (pessoas que frequentam a graduação), pós-graduando (pessoas que frequentam a pós-graduação) e assim sucessivamente. A mesma fórmula é usada para o cálculo do IPG para as diferentes condições (graduandos, graduados, pós-graduandos e pós-graduados), substituindo sexo pela variável cor/raça.

As pesquisas quantitativas, na maior parte dos estudos trabalham com as opções de autoclassificação como pretos e pardos, vide as publicações do IBGE. O uso do termo "negros" tem por finalidade a contraposição com as análises para o grupo de brancos. Vários estudos apresentam a categoria negro como de uso social, conforme descrito por Guimarães (2002). Neste trabalho, inclui-se na categoria "negros" os pretos e os pardos.

Inicialmente é fundamental analisar a caracterização populacional por cor/raça nos dois censos utilizados e que apresentam uma representativa diferenciação em sua composição. A partir desse quadro deve-se analisar os grupos de interesse: graduandos, graduados, pósgraduandos ou pós-graduados.

TABELA 2. Distribuição percentual por cor /raça da população geral, da parcela de graduandos e pós-graduandos. Brasil, 2000 e 2010.

\begin{tabular}{c|c|c|c|c|c|c}
\hline \multirow{2}{*}{ Cor/raça } & \multicolumn{2}{|c|}{ População Geral } & \multicolumn{2}{c|}{ Graduandos } & \multicolumn{2}{c}{ Pós-Graduandos } \\
\cline { 2 - 7 } & 2000 & 2010 & 2000 & 2010 & 2000 & 2010 \\
\hline Branca & 53,7 & 47,5 & 78,5 & 63,0 & 84,3 & 73,2 \\
\hline Negra & 44,7 & 50,9 & 19,5 & 35,3 & 13,3 & 24,9 \\
\hline Preta & 6,2 & 7,5 & 2,4 & 5,3 & 2,3 & 4,3 \\
\hline Parda & 38,5 & 43,4 & 17,2 & 30,0 & 10,9 & 20,6 \\
\hline
\end{tabular}

Fonte: Censo Demográfico, 2000 e 2010 (Microdados). (acessados via BME).

Na tabela 2 é observado um movimento de queda na participação dos brancos de 2000 para 2010, seja na população geral como nas parcelas que frequentam cursos de graduação e pós-graduação. Os brancos representavam 53,7\% da população brasileira no ano 2000 e passam para 47,5\% em 2010. Já os negros que representavam $44,7 \%$ da população no ano 2000 , sendo $6,2 \%$ pretos e $38,5 \%$ pardos, em 2010 , têm sua participação aumentada para $50,9 \%$ sendo $7,5 \%$ pretos e $43,4 \%$ pardos.

Quanto à participação de negros e brancos no contingente de graduandos do Ensino Superior, é notável o movimento ascendente dos negros. No ano 2000, eles representavam 19,5\% dos graduandos 
do país, enquanto em 2010, passam a representar 35,0\% da população nessa condição de escolaridade. Por outro lado, os brancos se conservam em um patamar bastante superior ao dos negros quanto ao quesito frequência a curso superior, mas a sua participação tem uma redução, passando de 78,5\% para 63,0\%.

Em relação ao contingente de brasileiros pós-graduandos, é perceptível também a evolução dos negros no período de 2000 a 2010. A porcentagem de negros nesse contingente passa de 13,3\% para $24,9 \%$. Como na comparação anterior, os brancos, embora exibam uma participação na população de pós-graduandos bastante superior a dos negros, apresentaram queda no período de $84,3 \%$ para $73,2 \%$ no período.

TABELA 3. Variação nas taxas de participação por cor/raça para população, pessoas que frequentam a graduação ou pós-graduação.

\begin{tabular}{|c|c|c|c|}
\hline \multirow{2}{*}{} & \multicolumn{3}{|c|}{ Variação 2000 a 2010 } \\
\cline { 2 - 4 } & População & Graduandos & Pós-graduandos \\
\hline Branca & $-0,7$ & 49,6 & 28,8 \\
\hline Preta & 35,9 & 369,8 & 184,2 \\
\hline Parda & 26,8 & 259,9 & 170,0 \\
\hline Negro & 28,1 & 270,1 & 172,5 \\
\hline Total & 12,3 & 84,8 & 48,1 \\
\hline
\end{tabular}

Fonte: Microdados do Censo Escolar 2000 e 2010. (Acessado via BME).

Nota: Os cálculos foram realizados considerando as faixas de 18 a 24 anos para Graduação e 25 a 64 para a Pós-graduação.

Desta forma, as taxas de variação para pretos e pardos (tabela 3) está bem acima da variação para o total da população, em especial na graduação, espaço de escolarização com maior crescimento na década analisada e descrita na literatura. Os números elevados de crescimento, em especial na graduação devem ser analisados com ressalvas, pois indicam que saímos de uma participação muito pequena desses grupos para uma participação mais equitativa nessas etapas de escolarização.

A Tabela 4 apresenta a distribuição de IPG e IPR para a população brasileira, com base em informações dos Censos Demográficos de 2000 e 2010, assim, as diferenças encontradas nas análises para os grupos de estudantes e titulados no ensino superior devem ser compreendidas em um contexto de relações de gênero e de desigualdades raciais, que, ao serem explicitadas, podem auxiliar na proposição de políticas públicas que produzam uma maior equidade entre os grupos, em especial para os negros. 
TABELA 4. Distribuição das pessoas por sexo, cor/raça, IPG e IPR - Brasil, 2000 e 2010

\begin{tabular}{|c|c|c|c|c|c|c|}
\hline \multirow[b]{2}{*}{ Sexo } & \multicolumn{3}{|c|}{2000} & \multicolumn{3}{|c|}{2010} \\
\hline & $\mathrm{N}$ & $\%$ & $I P G$ & $\mathrm{~N}$ & $\%$ & IPG \\
\hline Homens & 83.602 .317 & 49,2 & \multirow{3}{*}{1,03} & 93.406 .990 & 49,0 & \multirow{3}{*}{1,0} \\
\hline Mulheres & 86.270 .539 & 50,8 & & 97.348 .810 & 51,0 & \\
\hline Total & 169.872 .856 & 100,0 & & 190.755 .800 & 100,0 & \\
\hline Cor/raça & & & IPR & & & IPR \\
\hline Brancos & 91.298 .042 & 54,6 & \multirow{3}{*}{0,83} & 90.621 .281 & 48,3 & \multirow{3}{*}{1,07} \\
\hline Negros & 75.872 .428 & 45,4 & & 97.171 .614 & 51,7 & \\
\hline Total* & 167.170 .470 & 100,0 & & 187.792 .895 & 100,0 & \\
\hline
\end{tabular}

Fonte: Microdados do Censo Escolar 2000 e 2010 (acessados via BME).

Nota: * total exclui os amarelos, indígenas e sem indicação de cor; os três grupos totalizam 2.702 .385 pessoas (1,5\%) em 2000 e 2.962 .905 pessoas $(1,5 \%)$ em 2010.

Vale ressaltar que a participação de amarelos em 2010 é de $1,1 \%$ e de indígenas é de $0,4 \%$ no total da população brasileira. Dessa forma, optou-se por desconsiderá-los para a construção de um indicador que polarize e explicite a participação de brancos e negros.

Observa-se que o valor de IPG está dentro do intervalo de confiança em 2000 e 2010. O IPR sofre variação no período considerado, passando de 0,83 (predomínio de brancos) para 1,07 (predomínio de negros). O Censo de 2010 demarca uma inversão na participação por cor/raça na população brasileira, verificada desde a edição de 2008 da Pesquisa Nacional por Amostra de Domicílio (PNAD). Segundo Cunha (2012, p. 3):

Este fenômeno pode ser atribuído tanto a um diferencial de fecundidade - a taxa de fecundidade global das mulheres negras é de 2,1 e das brancas 1,6 filhos por mulher, no nível de reposição dos dois grupos -, e/ou pelo aumento sistemático de população que se autodeclara negra devido a um processo de conscientização da importância de assumir sua própria identidade.

Sergei Soares (2008) discute a questão da mudança na identificação racial da população brasileira na última década. Para o autor, tal mudança não se justifica apenas pelas questões de fecundidade, mas encontra explicação, principalmente, na alteração da autoclassificação da população: "Pode-se dizer que o que está acontecendo não é que o Brasil esteja tornando-se uma nação de negros, mas, sim, que está se assumindo como tal" (SOARES, 2008, p. 116). 
Essa questão não será aprofundada neste trabalho, mas precisa ser citada, pois as mudanças na distribuição de brancos e negros na população em geral repercutem diretamente nos diferentes índices de escolarização apresentados adiante e devem ser consideradas nas análises dos resultados encontrados por cor/raça.

Perante a paridade na população, ou de um pequeno predomínio de negros em 2010, o Gráfico 1 apresenta a distribuição de IPG e IPR para as diferentes etapas de escolaridade para 2000 e 2010. Entender o processo de ocupação dos espaços por sexo e cor/raça no ensino superior demanda uma análise, mesmo que superficial, das etapas anteriores de escolarização. Assim, a apresentação de informações de todo o percurso escolar auxilia na compreensão do observado na etapa mais elevada de escolarização: o ensino superior, em especial a pós-graduação.

GRÁFICO 1. IPG e IPR para estudantes por nível de escolaridade, Brasil, 2000 e 2010

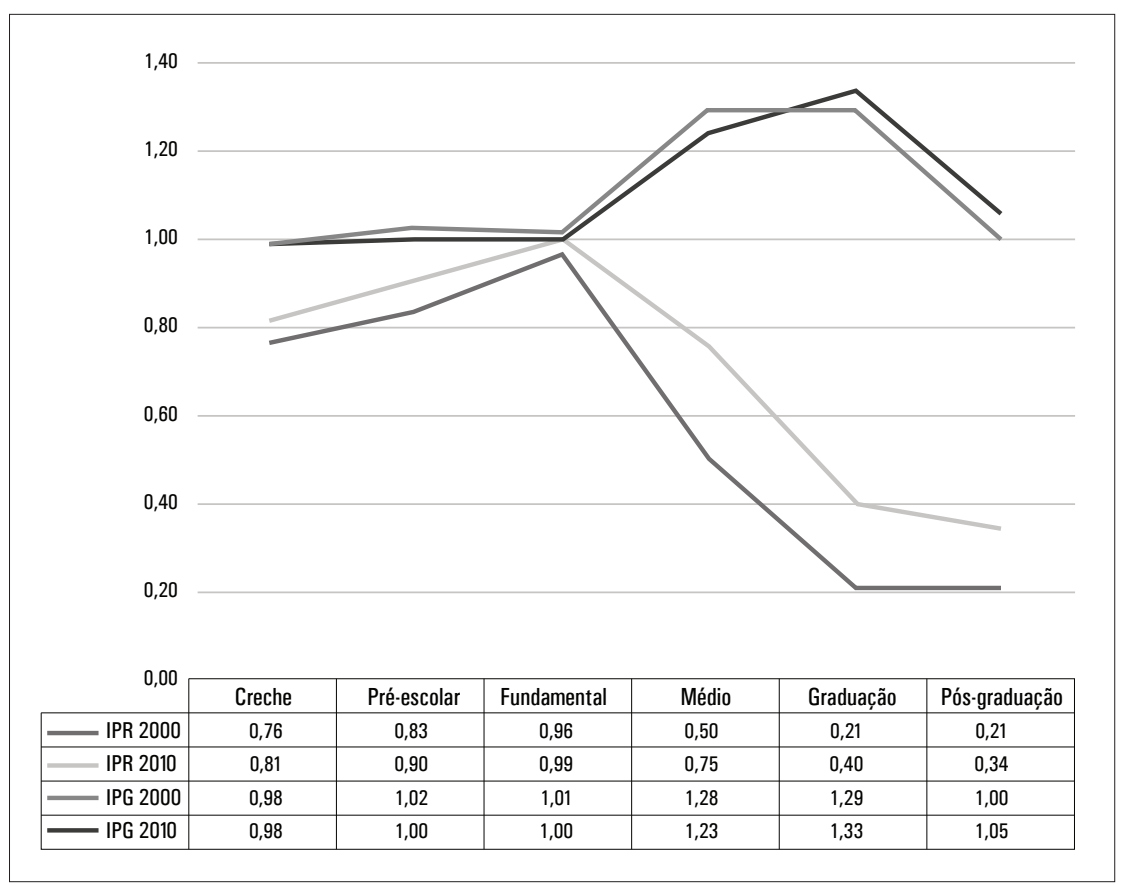

Fonte: Microdados de Censo Demográfico 2000 e 2010. (Acessada via BME).

Nota: as faixas etárias utilizadas foram: Creche de 0 a 3 anos; Pré-escolar ( 4 a 5 anos); Fundamental ( 6 a 14 anos); Médio (15 a 17 anos); Graduação (18 a 24 anos) e Pós-graduação (25 a 64 anos).

$\mathrm{Na}$ análise do Gráfico 1 não se observam diferenças no IPG de 2000 e 2010: as linhas praticamente se sobrepõem para todas as etapas. Até o ensino fundamental, as diferenças entre mulheres e homens estão dentro do intervalo de confiança. As diferenças entre os IPGs surgem a partir do ensino médio, mantendo-se favoráveis 
às mulheres também na graduação. Desta forma, não se verificam diferenças relevantes no período considerado, indicando estabilidade no acesso por sexo para os distintos níveis, entre 2000 e 2010.

Os resultados para o IPR necessitam de uma análise mais minuciosa. No total da população, parte-se em 2000 de uma desvantagem para os negros, índice de 0,83 , e atinge-se em uma vantagem, 1,07, em 2010 (Tabela 4). Só essa mudança, no total da população, pode influenciar as alterações nos IPRs encontrados, isto é, um número maior de pessoas se autodeclaram negras em 2010, na comparação com 2000, conforme descrito por Soares (2008) e citado anteriormente. Qual a influência na mudança da autoclassificação dos negros nos resultados encontrados nas diferentes etapas de escolarização? Em especial para os dados de 2010? Essa questão, como já ressaltado, é de fundamental importância, mas supera o escopo deste estudo e fica em aberto para novos estudos. O cálculo dos indicadores considera essas mudanças de classificação racial, ao trabalhar com o somatório dos grupos de cor/raça da população no denominador para o cálculo dos indicadores (quadro 1).

Considerando-se as diferentes etapas de atendimento, em 2010, os negros se aproximaram dos brancos no acesso à creche e à pré-escola. No ensino fundamental estão em paridade, o que pode ser entendido por ser a etapa de universalização na oferta de atendimento. No ensino médio as distâncias entre os grupos se amplia consideravelmente; enquanto em 2000 eram 50 negros para cada grupo de 100 brancos frequentando o ensino médio, em 2010 a relação é de 75 para 100. A melhora observada ainda mostra as marcas das desigualdades que constituídas nessa etapa (de frequência obrigatória, pós Emenda Constitucional n. 59) repercutem nos indicadores de acesso ao ensino superior: em 2000 para cada 100 brancos tinha-se 21 negros, índice que chaga a 40 em 2010. Na pós-graduação as distâncias são mantidas. A análise geral do gráfico indica que um intenso gargalo é apresentado no ensino médio, impossibilitando (ou dificultando) o acesso de negros as etapas mais elevadas de escolarização.

Um aspecto importante a ser explorado nesse artigo é a distribuição dos estudantes e titulados por região. A tabela 5 apresenta os resultados para o conjunto da população e deverá ser utilizada como linha de base para as análises dos grupos focalizados. Este cuidado é essencial, pois para o conjunto da população as distâncias entre os grupos de cor/raça por região já são representativas e diferenciadas e influenciam os resultados para os grupos de graduandos, graduados, pós-graduandos e pós-graduados. 
TABELA 5. IPG e IPR para o total da população, faixa de idade de 25 a 64 anos, por região - Brasil 2000 e 2010

\begin{tabular}{|c|c|c|c|c|c|c|}
\hline & \multicolumn{2}{|c|}{ IPG } & \multicolumn{2}{c|}{ IPR } & \multirow{2}{*}{$\begin{array}{c}\text { \% negros na } \\
\text { população } \\
\text { (2010) }\end{array}$} & $\begin{array}{c}\text { \% das } \\
\text { mulheres na } \\
\text { população } \\
\text { (2010) }\end{array}$ \\
\cline { 2 - 5 } Região & $\mathbf{2 0 0 0}$ & $\mathbf{2 0 1 0}$ & $\mathbf{2 0 0 0}$ & $\mathbf{2 0 1 0}$ & & \\
\hline Norte & 0,96 & 0,98 & 2,38 & 3,08 & 73,5 & 49,5 \\
\hline Nordeste & 1,09 & 1,08 & 1,97 & 2,39 & 69,4 & 52,0 \\
\hline Sudeste & 1,07 & 1,07 & 0,56 & 0,77 & 42,9 & 51,8 \\
\hline Sul & 1,04 & 1,05 & 0,17 & 0,25 & 19,9 & 51,2 \\
\hline Centro-0este & 1,03 & 1,04 & 0,95 & 1,32 & 55,7 & 50,9 \\
\hline Total & 1,06 & 1,06 & 0,76 & 1,01 & 49,5 & 51,5 \\
\hline
\end{tabular}

Fonte: Microdados do Censo Demográfico 2000 e 2010. (acessados via BME).

Segundo os valores não se observam diferenças relevantes no IPG entre 2000 e 2010 para o total da população (duas primeiras colunas). A análise do IPR já indica um enegrecimento da população e apresenta peculiaridades que merecem destaque: a região CentroOeste, por exemplo, de uma paridade $(0,95)$ passa a apresentar um predomínio dos negros, IPR de 1,32. A região Norte também merece atenção, já que o predomínio de negros na população passou de 2,28 (2000) para 3,08 (2010). De forma geral, são as regiões Norte e Nordeste que têm a maior participação de negros no total da população: respectivamente, $73,5 \%$ e $69,4 \%$. Resultado oposto é encontrado para a região Sul, com 19,9\% de negros em seu contingente populacional. O cruzamento dessas informações com as específicas para os níveis de escolaridade, em que as regiões Norte e Nordeste são as que apresentam as menores taxas de cobertura para a graduação é fundamental para a compreensão do quadro descrito: os negros não estão no ensino superior por que não conseguem acessar as vagas existentes, ou porquê estão em maior número em regiões em que não há oferta suficiente de vagas?

\section{A PÓS-GRADUAC̣ÃO E OS INDICADORES DE PARIDADE}

Considerando que o acesso à pós-graduação tem por condição necessária a finalização dos cursos de graduação, a Tabela 6 apresenta o IPG e o IPR para os graduados, pós-graduandos (estudantes de 
pós-graduação) e pós-graduados, comparando dados de 2000 e 2010. A faixa de idade, entre 25 e 64 anos, é a utilizada em consonância com o observado na literatura para a apresentação de informações para esses grupos de estudantes (BRASIL, 2010; CGEE, 2010).

TABELA 6. IPG e IPR por níveis de escolarização - Brasil 2000 e 2010, de 25 a 64 anos.

\begin{tabular}{l|c|c|c|c}
\hline \multirow{2}{*}{} & \multicolumn{2}{|c|}{ IPG } & \multicolumn{2}{c}{ IPR } \\
\cline { 2 - 5 } & $\mathbf{2 0 0 0}$ & $\mathbf{2 0 1 0}$ & $\mathbf{2 0 0 0}$ & $\mathbf{2 0 1 0}$ \\
\hline Graduados & 1,08 & 1,39 & 0,25 & 0,35 \\
\hline Estudantes de pós-graduação & 1,00 & 1,05 & 0,21 & 0,34 \\
\hline Pós-graduados & 0,73 & 0,92 & 0,17 & 0,23 \\
\hline Total (25 a 64 anos) & 1,06 & 1,06 & 0,76 & 1,01 \\
\hline
\end{tabular}

Fonte: Microdados de Censo Demográfico 2000 e 2010. (acessados via BME).

No IPG não se observam diferenças para o total da população de 25 a 64 anos nos períodos analisados, 1,06 tanto para 2000 como 2010 (última linha da tabela). $\mathrm{Na}$ análise por etapas de escolarização, as mulheres, que já eram maioria em 2000 para o grupo de graduados e estudantes de pós-graduação, ampliam o predomínio em 2010. No caso dos pós-graduados, a distância entre homens e mulheres diminui de 0,73 para 0,92 , com uma tendência para a paridade. É importante ressaltar que o total de titulados independe da idade de titulação: como as mulheres têm ocupado os espaços acadêmicos mais recentemente, é necessário um maior tempo para que o predomínio, já observado nas taxas de graduandos, repercute nas taxas do grupo de pós-graduados. A tendência é que as mulheres superem os homens também para esse universo, com o passar dos anos.

$\mathrm{Na}$ análise do IPR, a distância entre negros e brancos são maiores que as expressas entre mulheres e homens pelos valores do IPG, porém vêm diminuindo no período considerado. Essas mudanças podem ser consequência da alteração na autodeclaração de cor/raça das pessoas ou resultar da mudança na configuração racial dos cursos de graduação observada na década, com a implantação de programas de ação afirmativa. ${ }^{7}$

A influência dos programas de ação afirmativa na mudança da configuração racial na graduação e seus reflexos na pós-graduação são temas incipientes de pesquisa. São necessários novos estudos de monitoramento das políticas públicas de acesso ao ensino superior, com foco nos programas de pós-graduação, para dimensionar e avaliar suas influências na mudança de perfil dos graduandos e graduados no acesso e finalização dos programas de pós-graduação. 
A seguir são apresentadas informações em separado para o grupo de pós-graduandos e pós-graduados com a caracterização por região e categoria administrativa da instituição de ensino. Para a base de 2010, é possível também separar o tipo de pós-graduação frequentada (mestrado e doutorado).

\section{PÓS-GRADUANDOS (OU ESTUDANTES DE PÓS-GRADUAC̣ÃO)}

A tabela 7 apresenta os valores do IPG e IPR para o conjunto da população, na faixa etária de 25 a 64 anos, por região e grupo de pós-graduando, para os anos de 2000 e 2010.

TABELA 7. IPG e IPR dos pós-graduandos, faixa de idade de 25 a 64 anos, segundo a região e a categoria administrativa da instituição - Brasil 2000 e 2010

\begin{tabular}{c|c|c|c|c}
\hline \multirow{2}{*}{} & \multicolumn{2}{|c|}{ IPG } & \multicolumn{2}{c}{ IPR } \\
\cline { 2 - 5 } & $\mathbf{2 0 0 0}$ & $\mathbf{2 0 1 0}$ & $\mathbf{2 0 0 0}$ & $\mathbf{2 0 1 0}$ \\
\hline Região & & & & \\
\hline Norte & 1,00 & 1,08 & 0,28 & 0,45 \\
\hline Nordeste & 1,29 & 1,12 & 0,23 & 0,39 \\
\hline Sudeste & 0,94 & 0,99 & 0,15 & 0,32 \\
\hline Sul & 1,02 & 1,14 & 0,16 & 0,31 \\
\hline Centro-0este & 0,99 & 1,71 & 0,23 & 0,44 \\
\hline Total & 1,00 & 1,08 & 0,16 & 0,34 \\
\hline Categoria & & & & \\
\hline Particular & 1,03 & 1,04 & 0,23 & 0,33 \\
\hline Pública & 0,97 & 1,08 & 0,19 & 0,34 \\
\hline Total & 1,06 & 1,08 & 0,21 & 0,34 \\
\hline
\end{tabular}

Fonte: Microdados do Censo Demográfico 2000 e 2010. (acessados via BME).

Avaliando os resultados em comparação com a tabela 5 observa-se que o predomínio de negros nas regiões Norte e Nordeste não é mantido para o grupo de estudantes de pós-graduação. A melhora de desempenho (ou participação) dos negros é observável para todas as regiões, na comparação de 2000 a 2010, mas os sentidos em relação aos brancos são mantidos. O melhor resultado é observado nas regiões Norte e Centro Oeste em uma relação próxima de dois brancos para cada negro (na região Norte para cada grupo de 100 brancos tem-se 45 negros e no Centro Oeste, 44 negros). Para as regiões Sudeste e Sul a relação é três brancos para cada negro. Não se observam diferenças entre as categorias administrativas pública e particular: em 2000 a relação era de 5 brancos para cada negro e em 2010 a diferença cai de 3 para 1, independente do ano analisado. 
$\mathrm{Na}$ análise do IPG na pós-graduação, as mulheres apresentam uma maior participação em especial na região Centro Oeste e para o ano de 2010. Tal resultado demanda um estudo em separado para a compreensão da mudança observada entre 2000 (paridade) para 2010 (de cada 100 homens tem-se 171 mulheres). ${ }^{8}$ Para as outras regiões o predomínio feminino se consolida em 2010. A região Sudeste é a única em que se observa paridade $(0,99)$ em 2010. $\mathrm{Na}$ análise das categorias administrativas o predomínio feminino é encontrado, de forma sutil, nas públicas, com 108 mulheres para cada grupo de 100 homens.

A seguir são apresentadas informações para a base de 2010, incluindo o tipo de curso frequentado: mestrado ou doutorado, as categorias administrativas por tipo de curso. Na base de 2000 as informações para a pós-graduação não estão separadas entre mestrado e doutorado.

TABELA 8. IPG e IPR por tipo de graduação (mestrado ou doutorado), faixa de idade de 25 a 64 anos - Brasil, 2010

\begin{tabular}{c|c|c}
\hline & IPG & IPR \\
\hline Mestrado & 1,10 & 0,36 \\
\hline Doutorado & 0,96 & 0,29 \\
\hline Total & 1,05 & 0,34 \\
\hline
\end{tabular}

Fonte: Microdados do Censo Demográfico 2010. (acessados via BME).

A Tabela 8 indica o predomínio das mulheres nos cursos de mestrado e a paridade nos cursos de doutorado. No IPR, a presença de negros é maior no mestrado: são 36 negros para cada 100 brancos, ao passo que há 29 negros para cada 100 brancos no doutorado. $\mathrm{O}$ resultado reforça a tese de que as distâncias por cor/raça aumentam à medida que se sobe na escala de escolarização.

TABELA 9. IPG e IPR por tipo de graduação e categoria administrativa, faixa de idade de 25 a 64 anos - Brasil, 2010

\begin{tabular}{l|c|c|c}
\hline \multicolumn{2}{c|}{ Categoria administrativa } & IPG & IPR \\
\hline \multirow{3}{*}{ Pública } & Mestrado & 1,11 & 0,39 \\
\cline { 2 - 4 } & Doutorado & 0,94 & 0,29 \\
\cline { 2 - 4 } & Total & 1,04 & 0,34 \\
\hline \multirow{4}{*}{ Particular } & Mestrado & 1,09 & 0,33 \\
\cline { 2 - 4 } & Doutorado & 1,04 & 0,30 \\
\cline { 2 - 4 } & Total & 1,08 & 0,33 \\
\hline
\end{tabular}

Fonte: Microdados do Censo Demográfico 2010. (acessados via BME). 
A Tabela 9 apresenta a mesma informação distribuída pelas categorias administrativas (pública ou particular) de pertença dos grupos. No mestrado, o predomínio é feminino e ocorre independentemente da categoria analisada: 1,11 para a pública e 1,09 para a particular. No doutorado, a paridade é encontrada tanto nas instituições públicas $(0,94)$ como nas particulares $(1,04)$. O IPR indica uma maior participação dos negros nos cursos públicos de mestrado $(0,39)$ do que nos cursos particulares $(0,33)$. Para os cursos de doutorado, a participação dos negros independe da categoria: são 29 negros para cada 100 brancos que estudam tanto nas instituições públicas e 30 nas particulares.

TITULADOS: GRADUAÇÃO E PÓS-GRADUAC̣ÃO

As tabelas a seguir apresentam os resultados obtidos para os grupos de graduados ou titulados na graduação (potenciais candidatos à pós-graduação) como de pós-graduados, os que já finalizaram essa etapa. Esses resultados podem, com ressalvas, serem comparados com os obtidos para o grupo de estudantes.

TABELA 10. IPG e IPR por região, faixa de idade de 25 a 64 anos - Brasil, 2000 e 2010

\begin{tabular}{|c|c|c|c|c|c|}
\hline \multirow{2}{*}{\multicolumn{2}{|c|}{ Região }} & \multicolumn{2}{|c|}{ IPG } & \multicolumn{2}{|c|}{ IPR } \\
\hline & & \multirow{2}{*}{\begin{tabular}{|l|}
2000 \\
1,41
\end{tabular}} & \multirow{2}{*}{\begin{tabular}{|l|}
2010 \\
1,43
\end{tabular}} & \multirow{2}{*}{$\begin{array}{l}2000 \\
0,37\end{array}$} & \multirow{2}{*}{$\begin{array}{l}2010 \\
0,48\end{array}$} \\
\hline & Graduados & & & & \\
\hline & Pós-graduados & 0,66 & 0,88 & 0,26 & 0,28 \\
\hline \multirow{2}{*}{ Nordeste } & Graduados & 1,49 & 1,62 & 0,29 & 0,41 \\
\hline & Pós-graduados & 0,77 & 0,99 & 0,21 & 0,29 \\
\hline \multirow{2}{*}{ Sudeste } & Graduados & 1,48 & 1,28 & 0,24 & 0,31 \\
\hline & Pós-graduados & 0,70 & 0,88 & 0,14 & 0,21 \\
\hline \multirow{2}{*}{ Sul } & Graduados & 1,44 & 1,36 & 0,27 & 0,33 \\
\hline & Pós-graduados & 0,83 & 1,00 & 0,18 & 0,22 \\
\hline \multirow{2}{*}{ Centro-Oeste } & Graduados & 1,53 & 1,35 & 0,35 & 0,44 \\
\hline & Pós-graduados & 0,72 & 0,94 & 0,25 & 0,30 \\
\hline \multirow{2}{*}{ Total } & Graduados & 1,48 & 1,35 & 0,25 & 0,35 \\
\hline & Pós-graduados & 0,73 & 0,92 & 0,17 & 0,23 \\
\hline
\end{tabular}

Fonte: Microdados do Censo Demográfico 2000 e 2010. (acessados via BME).

A Tabela 10 apresenta as informações por região. As mulheres graduadas, que já eram maioria nas cinco regiões em 2000, mantêm o predomínio em 2010. Tal resultado deve ser analisado considerando o 
IPG do Ensino Médio e Superior (Gráfico 1), condições necessárias para o acesso à pós-graduação. Desta forma, o predomínio feminino se constrói ainda na educação básica.

Para o grupo de pós-graduados e predomínio é de homens, tanto em 2000 como 2010, com uma melhora de participação observada no último censo, com paridade para as regiões Nordeste e Sul. Estes resultados indicam que o acesso a pós-graduação é bem mais restrito e historicamente contam com uma maior presença de homens. Vale ressaltar que o acesso às etapas mais elevadas de escolarização é uma realidade para as mulheres em especial após os anos de 1980. Como a medida de pós-graduados é uma somatória de pessoas que alcançaram essa etapa de escolarização independente da data de titulação, a presença masculina ainda é predominante. Mas os resultados observados para os pós-graduandos indicam que tal quadro tende a se alterar nas próximas décadas.

Nas análises do IPR as distâncias observadas entre 2000 e 2010 marcam, de forma contundente, as desigualdades no acesso para esta etapa de escolarização. $\mathrm{Na}$ comparação com os resultados encontrados na tabela 5, o predomínio de negros, em especial nas regiões Norte e Nordeste não altera as distâncias entre os grupos de raça/cor. Os resultados, como os encontrados indicam uma melhora muito sutil nos indicadores, muito distante da "desejada" equidade no acesso às etapas mais elevadas de escolarização. A relação observada é de 3 brancos para cada negro independente da região analisada.

A Tabela 11 sintetiza os resultados para o país, separando os cursos de mestrado e doutorado e indicam o predomínio de mulheres graduados que tende a ocupar os espaços de mestrado (paridade) e ainda em uma relação desigual para o doutorado (são 77 mulheres para cada grupo de 100 homens). Para a questão racial, as desigualdades medidas no grupo de graduados, são ampliadas para os mestres e apresentam uma relação de 19 negros para cada grupo de 100 doutores brancos. Desta forma, a condição de "doutores" está em processo de ocupação pelas mulheres e em menor intensidade pelos negros.

TABELA 11. IPG e IPR para graduados e pós-graduados, faixa de idade de 25 a 64 anos - Brasil, 2010

\begin{tabular}{c|c|c|c}
\hline \multicolumn{2}{c|}{ Curso mais elevado concluído } & IPG & IPR \\
\hline \multicolumn{2}{c|}{ Graduados } & 1,35 & 0,35 \\
\hline \multirow{3}{*}{ Pós-graduados } & Mestrado & 0,98 & 0,24 \\
\cline { 2 - 4 } & Doutorado & 0,77 & 0,19 \\
\cline { 2 - 4 } & Total & 0,92 & 0,23 \\
\hline
\end{tabular}

Fonte: Microdados do Censo Demográfico 2010. (acessados via BME). 
Dentre as novidades do Censo Demográfico 2010, está a possibilidade de conhecer as áreas de formação dos titulados (graduados e pós-graduados), o que pode contribuir para a compreensão das diferentes inserções de homens, mulheres, brancos e negros no mercado de trabalho e nos diferentes espaços de produção social. A Tabela 12 apresenta as informações por áreas gerais de formação.

TABELA 12. IPG e IPR para graduados e pós-graduados, por áreas gerais de formação, faixa de idade de 25 a 64 anos- Brasil, 2010

\begin{tabular}{|c|c|c|c|}
\hline \multicolumn{2}{|c|}{ Áreas gerais de formação } & IPG & IPR \\
\hline \multirow{3}{*}{ Educação } & Graduados & 4,51 & 0,56 \\
\hline & Mestres & 3,80 & 0,35 \\
\hline & Doutores & 2,89 & 0,25 \\
\hline \multirow{3}{*}{$\begin{array}{l}\text { Humanidades } \\
\text { e Artes }\end{array}$} & Graduados & 2,72 & 0,44 \\
\hline & Mestres & 1,51 & 0,31 \\
\hline & Doutores & 1,15 & 0,24 \\
\hline \multirow{3}{*}{$\begin{array}{l}\text { Ciências Sociais, } \\
\text { Negócios e Direito }\end{array}$} & Graduados & 0,97 & 0,28 \\
\hline & Mestres & 0,81 & 0,20 \\
\hline & Doutores & 0,69 & 0,20 \\
\hline \multirow{3}{*}{$\begin{array}{c}\text { Ciências, } \\
\text { Matemática } \\
\text { e Computação }\end{array}$} & Graduados & 0,83 & 0,35 \\
\hline & Mestres & 0,78 & 0,28 \\
\hline & Doutores & 0,76 & 0,18 \\
\hline \multirow{3}{*}{$\begin{array}{l}\text { Engenharia, } \\
\text { Produção e } \\
\text { Construção }\end{array}$} & Graduados & 0,28 & 0,21 \\
\hline & Mestres & 0,40 & 0,19 \\
\hline & Doutores & 0,39 & 0,19 \\
\hline \multirow{3}{*}{$\begin{array}{l}\text { Agricultura e } \\
\text { Veterinária }\end{array}$} & Graduados & 0,37 & 0,25 \\
\hline & Mestres & 0,66 & 0,25 \\
\hline & Doutores & 0,58 & 0,16 \\
\hline \multirow{3}{*}{$\begin{array}{c}\text { Saúde e } \\
\text { Bem-estar social }\end{array}$} & Graduados & 2,12 & 0,30 \\
\hline & Mestres & 1,66 & 0,20 \\
\hline & Doutores & 0,94 & 0,15 \\
\hline \multirow{3}{*}{ Serviços } & Graduados & 1,20 & 0,37 \\
\hline & Mestres & 0,62 & 0,28 \\
\hline & Doutores & 0,29 & 0,15 \\
\hline
\end{tabular}

Fonte: Microdados de Censo Demográfico 2010. (acessados via BME). 
A análise do IPG indica um domínio das mulheres nas áreas da Educação, nos três níveis apresentados, assim como na Saúde e Bemestar social, áreas historicamente de predomínio feminino (BELTRÃO; TEIXEIRA, 2004; RICOLDI; ARTES, 2015, CGEE, 2010). A área de Engenharia, Produção e Construção apresenta o predomínio masculino, também para as três etapas, consideradas historicamente como áreas masculinas (LOMBARDI, 2005, 2006). O que sobressai na área das Engenharias é a maior presença feminina nos níveis mais elevados de escolarização: ao passo que a taxa de mulheres graduadas é de 29 para cada 100 homens, no grupo dos doutores esse índice é de 41 mulheres para cada 100 homens. Na área das Ciências, Matemática e Computação, a tendência a favor dos homens se verifica nos três níveis.

Os valores do IPR praticamente não se alteram nos três níveis considerados, nem por titulações nem por áreas, indicando que as desigualdades ainda são anteriores, isto é, estão no acesso ou na falta de acesso dos negros a essa etapa de escolarização. Os negros estão mais presentes nas áreas de maior predomínio das mulheres - Educação e Saúde - sendo que, no melhor quadro, são 56 negros para cada 100 brancos na Educação. O pior cenário reside nas Engenharias, com 21 negros para cada grupo de 100 brancos graduados. À medida que se sobe na escala de titulação, a presença de negros é menor: são 15 negros doutores nas áreas de Serviços e Saúde para cada 100 brancos.

\section{CONSIDERAÇ̃̃ES FINAIS}

O objetivo que permeia a utilização dos índices de paridade é dar visibilidade às diferenças entre homens e mulheres, brancos e negros. Se no conjunto da população brasileira há paridade entre os sexos e um sutil predomínio de negros em relação a brancos, o mesmo não ocorre quando se analisa o cenário educacional, sobretudo as etapas mais elevadas de escolarização. O uso de um indicador sintético demonstra de forma contundente as distâncias encontradas entre os grupos comparados. Se o acesso tende favoravelmente às mulheres nas etapas mais elevadas de escolarização, a situação para os negros ainda é crítica. Várias conquistas, também importantes, foram alcançadas no acesso de negros ao ensino superior brasileiro nas últimas décadas, porém muito ainda falta percorrer para a desejável equidade entre os grupos por cor/raça no acesso as etapas mais elevadas (e prestigiadas) de escolarização.

Como já mencionado, as diferenças entre homens e mulheres são apresentadas e discutidas em diferentes estudos, a exemplo dos relatórios de monitoramento global da Unesco. Contudo, a respeito 
das distâncias por cor/raça - embora haja um paralelismo com a ideia do IPG -, não há antecedente. Desse modo, as discussões aqui apresentadas acerca dos valores de IPR devem ser compreendidas na interface com outras variáveis, em especial como a distribuição por região, com predomínio dos negros no Norte e no Nordeste. De forma sucinta, as distâncias observadas nesse estudo entre o acesso e finalização das etapas na pós-graduação é o quanto se precisa alterar para que se alcance a paridade desejada, em especial para os negros.

No caso das mulheres, as diferenças poráreas de conhecimento, que podem ser associadas a prestígio e a renda nas diferentes carreiras, também necessitam ser mais bem estudadas.

O grande conjunto de informações quantitativas distribuídas no artigo tem por objetivo demonstrar o quanto o acesso a uma determinada etapa de escolarização - no caso aqui descrito, do ensino superior, em especial na pós-graduação - precisa ser desagregado em diferentes aspectos (ou variáveis) para sua melhor compreensão. Temse clareza que apresentar essas distâncias em números não é simplificar a discussão sobre desigualdades raciais, discriminação racial ou racismo existentes no país. Trata-se, ao contrário, de um indicador do quanto se faz necessário mudar. Compreender as diferenças, monitorar as políticas já desenvolvidas e propor novas ações para sua superação constituem os novos desafios a serem enfrentados a fim de alcançar a desejada equidade no acesso e na finalização das diferentes etapas do ensino superior brasileiro. Os índices de paridade podem ajudar neste processo.

\section{REFERÊNCIAS}

ANDRADE, C.; DACHS, J. N. Acesso à educação por faixas etárias segundo renda e cor/ raça. Caderno de Pesquisa, n. 37, 2007.

ARTES, A. Desigualdades de cor/raça e sexo entre pessoas que frequentam e titulados na pós graduação brasileira: 2000 e 2010. Relatório de Pesquisa, Fundação Carlos Chagas, SP, 2015.

ARTES, A. C. A.; CARVALHO, M. P. de. O trabalho como fator determinante da defasagem escolar dos meninos no Brasil: mito ou realidade? Cadernos Pagu, Campinas, v. 34, p. 4174, jan./jun. 2010.

BELTRÃO, K.; TEIXEIRA, M. de P. O vermelho e o negro: raça e gênero na universidade brasileira - uma análise da seletividade das carreiras a partir dos censos demográficos de 1960 a 2000. Texto para discussão, n. 1052, Rio de Janeiro, Ipea, out. 2004.

BRASIL. Ministério da Educação. Plano Nacional de Pós-graduação (PNPG) 20112020. Brasília, DF: Ministério da Educação, dez. 2010. 
CARVALHO, M. P. de. Avaliação escolar, gênero e raça. Campinas: Papirus, 2009.

CENTRO DE GESTÃO E ESTUDOS ESTRATÉGICOS - CGEE. Doutores 2010: estudo da demografia da base técnico-científica brasileira. Brasília, DF: CGEE, 2010.

CUNHA, E. M. G. P. Brasil está reduzindo suas disparidades raciais? In: ENCONTRO NACIONAL DE ESTUDOS POPULACIONAIS: transformações na população brasileira: complexidades, incertezas e perspectivas, 18., Águas de Lindoia, 2012. Anais... Águas de Lindoia: Abep, 2012.

DIEESE, Mapa da população negra no mercado de trabalho. 1999.

FERES JR., J. (org.). Ação afirmativa no ensino superior brasileiro hoje: análise de desenho institucional 2011. Gemaa - Grupo de Estudos Multidisciplinares da Ação Afirmativa IESP/UERJ, 2011.

FRASER, N. "Reconhecimento sem ética.” Lua Nova 70 (2007): 101-138.

GUIMARÃES, A. S. Classes, raças e democracia. São Paulo, Editora 34, 2002.

GOMES, N. L. O movimento negro no Brasil: ausências, emergências e a produção dos saberes. doi: 10.5007/2175-7984.2011 v.10, n.18, p.133. Política \& Sociedade, v. 10, n. 18, p. 133-154, 2011.IBGE, Censo Demográfico. Microdados, 2010.

IBGE. Censo Demográfico. Microdados, 2000.

JANNUZZI, P. de M. Indicadores para diagnóstico, monitoramento e avaliação de programas sociais no Brasil. Revista do Serviço Público, Brasília, v. 56, n. 2, p. 137-160, abr. 2005.

LOMBARDI, M. R. Perseverança e resistência: a engenharia como profissão feminina. Tese (Doutorado em Educação) - Universidade Estadual de Campinas, Campinas, 2005.

LOMBARDI, M. R. Engenheiras brasileiras: inserção e limites de gênero no campo profissional. Cadernos de Pesquisa, v. 36, n. 127, p. 173-202, jan./abr. 2006.

MAGALHÃES, A. Trabalho e educação: os efeitos da educação sobre o processo de estratificação social entre brancos e não brancos no Brasil. $1^{\circ}$ Seminário Nacional de Sociologia e Política, UFPR, 2009.

MANCEBO, D.; SILVIA JR., J. dos Reis; OLIVEIRA, João Ferreira. (org.) Reformas e Políticas: educação superior e pós-graduação no Brasil. Alínea, 2008.

MOEHLECKE, S. Ação Afirmativa: história e debates no Brasil. Cadernos de Pesquisa. n. 117 p. 197-219, nov 2002.

MUNANGA, K. Uma abordagem conceitual das noções de raça, racismo, identidade e etnia. Cadernos Penesb, v. 5, p. 15-34, 2004.

PAIXÃO, M. (org.). Relatório Anual das Desigualdades Raciais no Brasil: 2009-2010. UERJ, 2010. 
RICOLDI, A.; ARTES, A. Novos lugares da desigualdade? Caracterização do ensino superior sob a interface gênero e raça/cor na atualidade. Relatório de pesquisa. São Paulo: Fundação Carlos Chagas, 2015.

ROSEMBERG, F. O branco no IBGE continua branco na ação afirmativa. Estudos Avançados 18(50), 2004.

ROSEMBERG, F. Desigualdades de gênero e raça no sistema educacional brasileiro. In: CONFERENCE ON ETHINICITY RACE, GENDER AND EDUCATION, Lima, 2002.

ROSEmberg, F. Ação Afirmativa no Ensino Superior Brasileiro. Programa de Ações Afirmativas em Debate, UFScar, 2006.

SANTAGADA, S. Indicadores sociais: contexto social e breve histórico. Revista FEE, v. 20, n. 4, p. 245-255, 1993.

SANTOS, A. M. dos. Vozes e silêncio do cotidiano escolar: análise das relações raciais entre alunos negros e não negros em duas escolas públicas no município de Cárceres. Dissertação de mestrado, UFMT, 2005.

SEADE. Os negros no mercado de trabalho na região metropolitana de São Paulo. Novembro de 2012.

SILVÉRIO, V. R. S. et al. Educação e ações afirmativas: entre a injustiça simbólica e a injustiça econômica. 2003

SOARES, S. A demografia da cor: a composição da população brasileira de 1890-2007. In: THEODORO, M. (org.). As políticas públicas e a desigualdade racial no Brasil: 120 anos após a abolição. Brasília, DF: Ipea, 2008.

SOLIGO, V. Indicadores: conceito e complexidade do mensurar em estudos de fenômenos sociais. Est. Aval. Educ., São Paulo, v. 23, n. 52, p. 12-25, 2012.

UNESCO. Relatório de monitoramento global Educação para Todos, 2003-2004. São Paulo: Moderna, 2004.

UNESCO. Relatório de monitoramento global Educação para Todos, 2003-2004. São Paulo: Moderna, 2015.

\section{NOTAS}

${ }^{1} \mathrm{O}$ IDEB reúne em um mesmo indicador numérico valores referentes ao fluxo escolar e desempenho dos alunos em exames de proficiência. Divulgado a cada dois anos, estabelece metas a serem alcançadas paras escolas para se chegar a índices educacionais de países da OCDE em 2022.

${ }^{2} \mathrm{O}$ conceito de ação afirmativa utilizado é (...) uma ação reparadora/compensatória ou preventiva, que busca corrigir uma situação de discriminação e desigualdade infringida a certos grupos do passado, presente e futuro, durante um período limitado. A ênfase em um ou mais desses aspectos dependerá do grupo visado e do contexto histórico e social (MOEHLECKE, 2002, p. 203.) 
${ }^{3}$ O Prouni é um programa do Ministério da Educação, criado pelo Governo Federal em 2004, que concede bolsas de estudo integrais e parciais (50\%) em instituiçoes privadas de ensino superior, em cursos de graduação e sequenciais de formação específica, a estudantes brasileiros, sem diploma de nível superior. O Fies é um programa do Ministério da Educação destinado a financiar a graduação na educação superior de estudantes matriculados em cursos superiores não gratuitas na forma da Lei 10.260/2001. Podem recorrer ao financiamento os estudantes matriculados em cursos superiores que tenham avaliação positiva nos processos conduzidos pelo Ministério da Educação.

${ }^{4} \mathrm{O}$ conceito de paridade utilizado aproxima-se do apresentado por Nancy Fraser (2007) " condição de ser um par, de estar em igual condição com os outros, de estar partindo do mesmo lugar” (pag. 118) .

${ }^{5}$ Taxa bruta de escolarização (TBE): número de alunos matriculados em determinado nível de educação, independentemente de idade, expresso como porcentagem da população pertencente ao grupo etário que oficialmente corresponde a esse nível de educação. Para o nível superior, é utilizada a população no grupo etário de zero a cinco anos acima da idade de conclusão do ensino médio. A TBE pode ultrapassar 100\% em virtude de ingresso precoce ou tardio e/ou repetência (UNESCO, 2015, p. 425).

${ }^{6} \mathrm{http}: / /$ web.observatoriodasmetropoles.net/index.php?option $=$ com_content\&view $=$ artic le\&id=45\&Itemid=114\&lang $=$ pt acessado em 19/09/2013.

${ }^{7}$ Ver Moechlecke (2002), Silvério (2002), Rosemberg (2004), Mancebo Jr., Silva e Oliveira (2008), Feres Jr. (2011).

${ }^{8}$ Segundo o BME este resultado é resultado da predominância de mulheres no mestrado, com um total de 7.134 para 2.881 homens)

Submetido: $15 / 03 / 2018$

Aprovado: 28/08/2018

Contato:

Amélia Cristina Abreu Artes

Fundação Carlos Chagas

Av. Prof. Francisco Morato, no 1565, Jd. Guedala

São Paulo $|\mathrm{SP}|$ Brasil

CEP 05.513-900 